\title{
Prospective factors contribute little to within-session changes in responding
}

\author{
FRANCES K. MCSWEENEY, JEFFREY N. WEATHERLY, and SAMANTHA SWINDELL \\ Washington State University, Pullman, Washington
}

\begin{abstract}
Five rats pressed levers for food delivered by a multiple variable interval 1-min variable interval 1min schedule. In the unpredictable conditions, sessions were $20,40,60,80$, or $100 \mathrm{~min}$ long, determined randomly at the beginning of each session. In the predictable conditions, each of these session durations was presented for 15 consecutive sessions. Rate of responding changed systematically within the session even when the end of the session was unpredictable. This implies that prospective factors related to anticipation of the end of the session are not necessary for producing withinsession changes in responding. Within-session patterns of responding were also similar for the predictable and unpredictable conditions. This suggests that prospective factors contributed little to the form of the within-session patterns under the present conditions.
\end{abstract}

Psychologists often study measures of behavior that are averaged over an experimental session. This is particularly true in operant conditioning, in which the average rate of responding is studied frequently (e.g., Herrnstein, 1970). Recently, the exclusive use of average measures has been questioned by the observation of large and systematic changes in responding within experimental sessions (McSweeney \& Roll, 1993). Although such changes have been known about for many years, they have been treated as problems to be controlled by giving "warmup" trials (e.g., Hodos \& Bonbright, 1972) or time to adapt to the apparatus (e.g., Papini \& Overmier, 1985), rather than as phenomena to be studied.

Further consideration suggests that within-session changes deserve study in their own right. First, these changes may be as large as or larger than those usually studied by operant psychologists. For example, the rate at which rats press keys for sweetened condensed milk has changed by as much as $450 \%$ during experimental sessions (McSweeney, Hatfield, \& Allen, 1990). To put this in perspective, Catania and Reynolds (1968, Experiment 1) varied the programmed rate of reinforcement from 8.4 to 300 reinforcers per hour and observed only approximately a doubling of response rate. Second, within-session changes may be highly orderly, occurring for individual subjects responding in individual sessions (e.g., McSweeney \& Hinson, 1992). They may also occur

This material is based on work supported by the National Science Foundation under Grant IBN-9207346. The treatment of the experimental subjects was approved by the Washington State University Institutional Animal Care and Use Committee before the experiment was conducted. Reprints may be obtained from F. K. McSweeney, Department of Psychology, Washington State University, Pullman, WA 99164-4820. throughout the session, not just at the beginning (e.g., McSweeney et al., 1990). Third, within-session changes occur quite generally. They have been reported for a wide variety of species, procedures, responses, and reinforcers (e.g., McSweeney \& Roll, 1993). Finally, as discussed elsewhere, these changes may have a number of important theoretical and methodological implications (see, e.g., McSweeney \& Roll, 1993). To give only one example, they challenge both molar (e.g., Herrnstein, 1970) and molecular (e.g., Hinson \& Staddon, 1983) theories. Molecular theories are challenged because these theories must account for within-session changes if they are to reach their goal of describing behavior on a moment-by-moment basis. Molar theories are challenged because within-session changes imply that the primary variable used in these theories, rate of responding averaged over the session, masks strong regularities in behavior at a more molecular level.

The variables that produce within-session changes in responding are unknown. Potentially contributing variables may be broadly classified into two categories: retrospective and prospective. Retrospective factors are those that occur earlier than the time at which responding is examined. For example, subjects may respond at a particular rate at a particular time in the session because the earlier delivery of reinforcers has produced a certain amount of arousal (Killeen, Hanson, \& Osborne, 1978) or satiation (Reese \& Hogenson, 1962). Alternatively, subjects may respond at a particular rate because prior responding has either "warmed up" their muscles or produced fatigue (Mosso, 1903/1906).

Prospective factors occur after the time at which responding is examined. Later events may come to influence earlier behavior through experience of the experimental procedure. For example, responding might slow 
late in a session, as subjects anticipate the feedings that often follow operant sessions (but see McSweeney et al., 1990). Responding for a weak reinforcer (small amounts of food in the session) is often suppressed when it is followed by a stronger reinforcer (large postsession feedings; e.g., Flaherty \& Checke, 1982; Williams, 1983). Alternatively, responding might decline late in the session if aversive events (e.g., handling by the experimenter) accompany the end of the session. Operant responding slows during stimuli that predict aversive events (e.g., Estes \& Skinner, 1941).

In the present experiment, we separated the contributions of retrospective and prospective factors to withinsession changes in responding by making the ends of the sessions unpredictable. Factors associated with anticipation of the end of a session cannot occur when the end of the session is unpredictable. Therefore, within-session changes in responding should not occur if they are produced by these prospective factors. In contrast, retrospective factors that accumulate over the session should not be altered by making the end of the session unpredictable. Therefore, within-session changes should not be changed if they are produced by retrospective factors.

\section{METHOD}

\section{Subjects}

The subjects were 5 experimentally naive rats bred from Sprague Dawley stock in the Johnson Tower Vivarium at Washington State University. They were maintained at approximately $85 \%$ of their freefeeding body weights by postsession feedings, given when all subjects had finished the daily session. Subjects were approximately 120 days old at the start of the experiment.

\section{Apparatus}

The apparatus was a standard two-lever experimental enclosure for rats, $20 \times 24.5 \times 24.5 \mathrm{~cm}$. A $5 \times 5.5 \mathrm{~cm}$ opening, which allowed access to food, was centered on the front panel, $0.5 \mathrm{~cm}$ above the floor Two $4 \times 1.5 \mathrm{~cm}$ levers appeared $2.5 \mathrm{~cm}$ from this opening, one on each side. The levers were $5 \mathrm{~cm}$ above the floor and extended $1.5 \mathrm{~cm}$ into the enclosure. A 2-cm-diameter light was located $2.5 \mathrm{~cm}$ above each lever. A third $2-\mathrm{cm}$-diameter light was centered on the front panel, $4 \mathrm{~cm}$ from the ceiling. The houselight was another $2-\mathrm{cm}$-diameter light, located in the center of the ceiling. The apparatus was enclosed in a sound-attenuating chamber, and a ventilating fan masked noises from outside of the chamber. A SYM microcomputer, located in another room, controlled the experimental events and recorded the data.

\section{Procedure}

Subjects were trained to press the right lever in a shaping by successive approximations procedure. The rate of reinforcement scheduled for leverpressing was gradually reduced until subjects responded on a variable interval (VI) 1 -min schedule. Then the experimental procedure began.

During all experimental conditions, pressing the right lever was reinforced by food (two $45-\mathrm{mg}$ Noyes pellets) delivered by a multiple VI 1-min VI 1-min schedule. Reinforcers were scheduled according to a 25-interval Fleshler and Hoffman (1962) series. The light above the right lever was on during the first component and off during the second component. Components alternated every $5 \mathrm{~min}$. These experimental details were selected because they have produced robust within-session changes in responding in the past (see, e.g., McSweeney, 1992)

During the unpredictable conditions, the computer randomly selected a session duration of $20,40,60,80$, or $100 \mathrm{~min}$ at the beginning of the session for each subject. Sessions were conducted daily, 5 to 6 times per week, until each subject had received each session duration at least 30 times. During the predictable conditions, subjects were exposed to 15 consecutive sessions of each duration. The predictable sessions were conducted after the unpredictable ones so that previous experience with predictability would not confound the results for the unpredictable conditions. The order of presentation of the predictable session durations was counterbalanced across subjects. Fifteen sessions were conducted instead of 30 for the predictable conditions, to try to ensure that all subjects lived long enough to complete the experiment. Past results had indicated that within session changes should occur when 15 sessions were conducted (e.g., McSweeney \& Hinson, 1992).

\section{RESULTS AND DISCUSSION}

Figure 1 presents the rates of responding (responses per minute) as a function of successive components for each unpredictable session duration. The results are those for the mean of all subjects responding during Sessions 26-30 for which each session duration was presented to each subject. Each function presents the results for a different session duration.

Figure 2 presents the rates of responding (responses per minute) for the unpredictable (solid line) and predictable (dashed line) conditions as a function of successive components for each session duration. The results are those for the mean of all subjects responding during Sessions 11-15 (predictable conditions) or Sessions 26-30 (unpredictable conditions) for which each session duration was presented to each subject. Each set of axes presents the results for one session duration. The results presented in Figures 1 and 2 for the mean of all subjects also represent those for individual subjects.

Table 1 contains the results of two-way (condition $\times$ component) repeated measures analyses of variance (ANOVAs) applied to the rates of responding by indi-

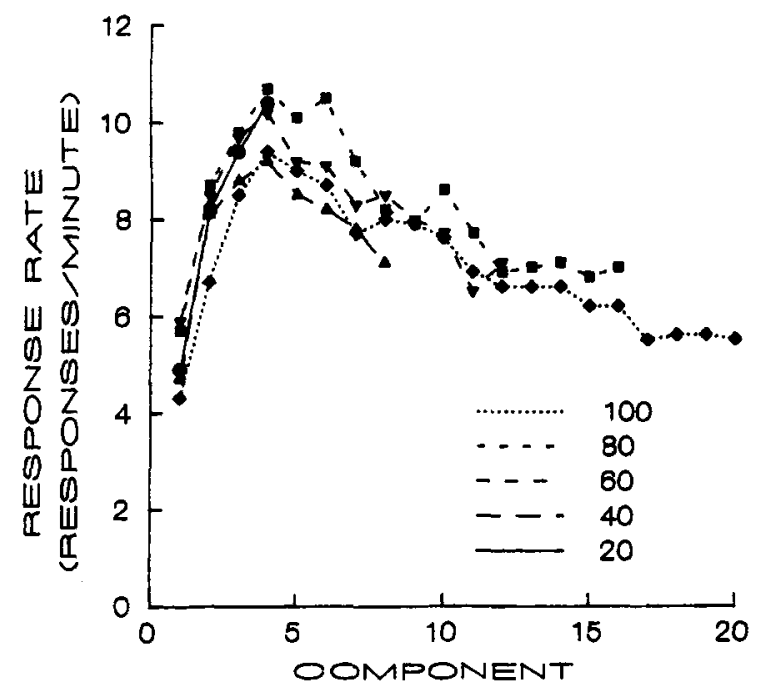

Figure 1. Rates of responding (responses per minute) as a function of successive components for each session duration when the sessions terminated unpredictably. All results are those for the mean of all subjects responding during Sessions 26-30 for which each session duration was presented to each subject. 

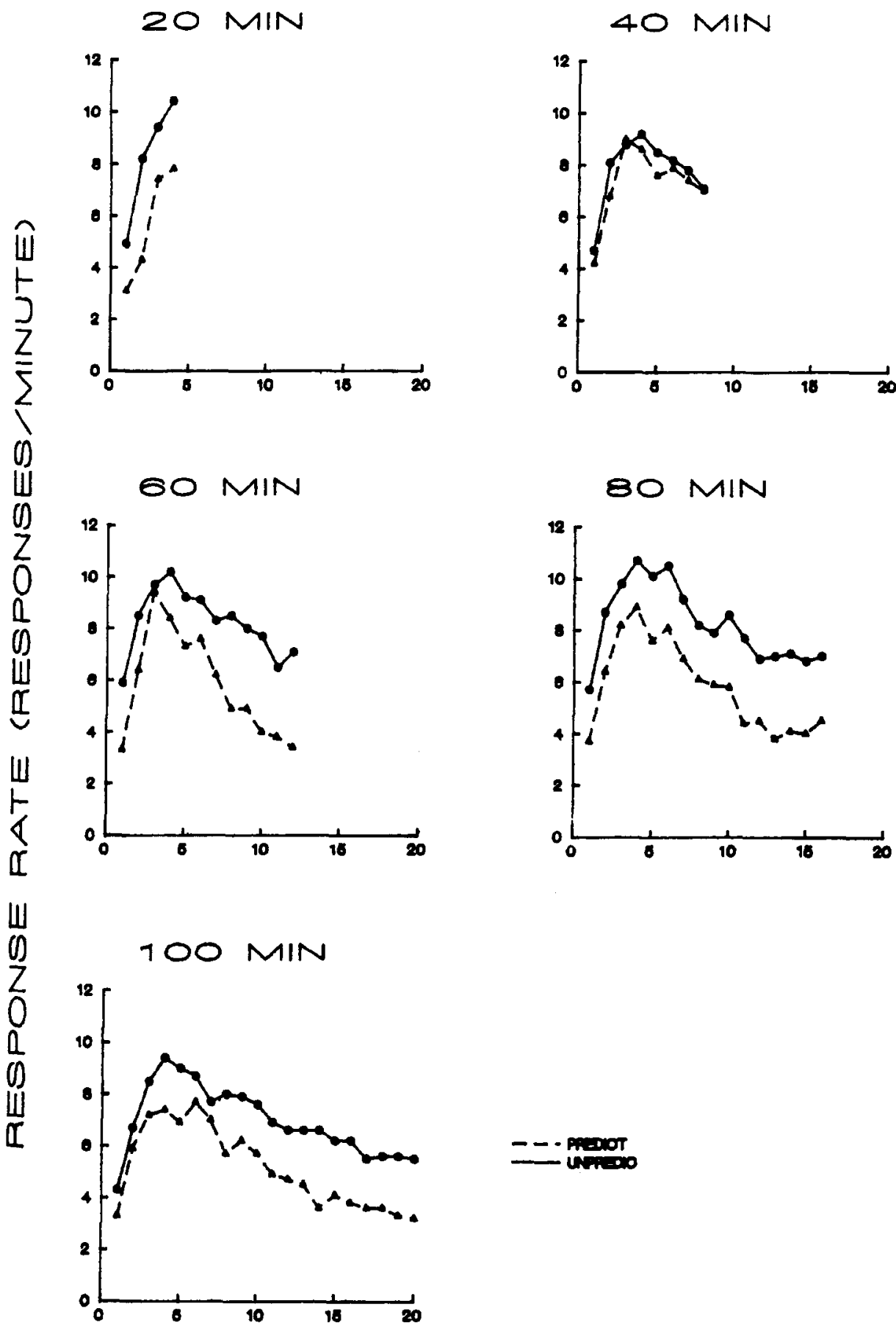

\section{OOMPONENT}

Figure 2. Rates of responding (responses per minute) for the unpredictable (solid line) and the predictable (dashed line) session durations as a function of successive components. The results are those for the mean of all subjects responding during Sessions 11-15 (predictable) or Sessions 26-30 (unpredictable) for which each session duration was presented to each subject. Each set of axes presents the results for one session duration.

vidual subjects during successive components in the session. The ANOVAs in the right column compare responding for each unpredictable session duration with responding during the same predictable session dura- tion. The ANOVAs in the left column compare responding during each unpredictable duration with responding during the same part of the just longer unpredictable duration. That is, responding during the 20 -min unpre- 
Table 1

Results of Two-Way (Condition $\times$ Component) Repeated Measures Analyses of Variance Applied to the Rates of Responding by Individual Subjects During Successive Components

\begin{tabular}{cll} 
Duration & \multicolumn{1}{c}{$\begin{array}{c}\text { Unpredictable Versus Next } \\
\text { Larger Unpredictable }\end{array}$} & \multicolumn{1}{c}{$\begin{array}{c}\text { Unpredictable Versus } \\
\text { Predictable }\end{array}$} \\
\hline 20-min condition & $F(1,4)=0.35, p<.59$ & $F(1,4)=2.37, p<.20$ \\
component & $F(3,12)=8.69, p<.002^{*}$ & $F(3,12)=9.13, p<.002^{*}$ \\
interaction & $F(3,12)=1.21, p<.35$ & $F(3,12)=2.84, p<.08$ \\
40-min condition & $F(1,4)=0.97, p<.38$ & $F(1,4)=0.46, p<.53$ \\
component & $F(7,28)=7.49, p<.001^{*}$ & $F(7,28)=5.32, p<.001^{*}$ \\
interaction & $F(7,28)=0.30, p<.95$ & $F(7,28)=0.54, p<.80$ \\
60-min condition & $F(1,4)=0.42, p<.55$ & $F(1,4)=3.14, p<.15$ \\
component & $F(11,44)=5.70, p<.001^{*}$ & $F(11,44)=7.06, p<.001^{*}$ \\
interaction & $F(11,44)=1.10, p<.38$ & $F(11,44)=1.91, p<.06$ \\
80-min condition & $F(1,4)=0.64, p<.47$ & $F(1,4)=1.80, p<.25$ \\
component & $F(15,60)=5.01, p<.001^{*}$ & $F(15,60)=8.15, p<.001^{*}$ \\
interaction & $F(15,60)=1.15, p<.33$ & $F(15,60)=0.40, p<.98$ \\
100 -min condition & & $F(1,4)=8.74, p<.04^{*}$ \\
component & & $F(19,76)=5.84, p<.001^{*}$ \\
interaction & & $F(19,76)=0.68, p<.82$ \\
\hline${ }^{*} p<.05$. & &
\end{tabular}

dictable condition was compared with responding during the first $20 \mathrm{~min}$ of the 40 -min unpredictable condition.

The main effect of component was always significant in Table 1, indicating that responding changed within experimental sessions. Although Figure 2 shows that responding was often slower during the predictable than during the unpredictable conditions, the main effect of condition was significant only for the 100 -min sessions. Many factors may have produced this significant effect. For example, subjects were older during the predictable than during the unpredictable conditions. Older subjects may have had more difficulty responding for as long as $100 \mathrm{~min}$.

The interaction between condition and component approached, but did not reach, significance for the comparisons between the predictable and unpredictable conditions when sessions were 20 or 60 min long. All other interactions were not significant, indicating that the within-session patterns of responding did not differ during predictable and unpredictable conditions, or during comparable parts of unpredictable sessions of different durations. The failure of within-session patterns to differ during these conditions implies that these patterns are quite stable. No significant changes were found even though the different conditions were conducted at different points in the animals' lives and for different numbers of sessions.

The results presented in Figure 1 and Table 1 show that prospective factors related to the end of the session are not necessary to produce within-session changes in responding. Significant within-session changes occurred even when those factors were not present (unpredictable conditions).

The results presented in Figure 2 and Table 1 suggest that prospective factors contributed little to within-session changes under the present conditions. Within-session response patterns did not differ significantly, regardless of whether prospective factors were present (predictable conditions) or not (unpredictable conditions). This conclusion must be qualified in two ways, however. First, it seems reasonable to assume that the choice of procedural details would alter the contribution of prospective factors. For example, anticipation of the end of the session might have had some effect on within-session patterns if rats had been given very large postsession feedings. The present results show only that prospective factors contributed little during the present relatively standard operant procedure.

Second, it might be argued that prospective factors contributed little because the predictable sessions were conducted after the unpredictable sessions. According to this argument, subjects learned that session length was unpredictable during the unpredictable conditions, and this learning intefered with their ability to detect the change of conditions when session length became predictable. The within-session patterns of responding were similar during the predictable and unpredictable conditions because subjects did not discriminate the change of conditions, not because prospective factors contributed little to producing these changes.

This argument seems unlikely. The qualitative properties of within-session changes in responding are similar when subjects respond on sessions of predictable length regardless of whether those sessions have (present experiment) or have not (McSweeney, 1992; McSweeney, Roll, \& Cannon, 1994) been preceded by sessions of unpredictable duration. In all cases, responding increases to a peak and then decreases within sessions. The peak response rate is reached at a constant time after the beginning of the session (approximately $20 \mathrm{~min}$ for rats), not at a time that is proportional to session length. These results have been highly replicable. They have been found regardless of whether pigeons peck keys for mixed grain (McSweeney et al., 1994), rats press levers for Noyes pellets (McSweeney et al., 1994), or rats press 
keys for sweetened condensed milk (McSweeney, 1992). Therefore, within-session patterns of responding do not seem to differ in important ways, regardless of whether subjects have had prior exposure to unpredictable session durations (the present study) or not (McSweeney, 1992; McSweeney et al., 1994).

The present results show that factors related to anticipation of the end of the session are not necessary for producing within-session changes in responding. They do not dismiss the possibility that prospective factors unrelated to the end of the session contributed, but it is difficult to imagine what those factors might be. As the end of the session approaches, the existence of prospective (future) factors that are not related to the end of the session becomes increasingly unlikely. It seems more likely that within-session changes in responding are produced by retrospective factors that accummulate from the beginning of the session than that they are produced by unidentified prospective factors.

Some past results also support the idea that retrospective factors produce within-session changes. McSweeney (1992) reported that responding increased and then decreased within sessions even during the first experimental session. This session was preceded only by earlier sessions of shaping. Because prospective factors require the anticipation of future events, they can develop only after experience of the procedure. Therefore, they could not be present during the first experimental session. In contrast, retrospective factors do not necessarily require experience and therefore could be present during the first session of training. Future experiments should specify the nature of the retrospective factors that contribute to within-session changes in responding. (See the present introduction and McSweeney \& Roll, 1993, for several potential explanations.)

As argued earlier, the present results are consistent with the finding that the peak rate of responding occurs at a constant time after the beginning of the session, not at a time that is proportional to session length (e.g., McSweeney, 1992; McSweeney et al., 1994). Responding usually peaked during the third or fourth component shown in Figures 1 and 2, regardless of session length. Therefore, this finding is true regardless of whether the end of the session is predictable (Figure 2) or unpredictable (Figures 1 and 2), and regardless of whether component duration is constant (present experiment) or varies with session duration (McSweeney, 1992; McSweeney et al., 1994). Finding peak responding at an absolute time since the beginning of the session may eventually distinguish within-session changes in responding from many conditioning phenomena. Responding on most con- ditioning procedures is governed by relative, not absolute, time (e.g., FI scallops, Schneider, 1969; responding during classical conditioning procedures-e.g., Balsam, 1984).

\section{REFERENCES}

Balsam, P. (1984). Relative time in trace conditioning. In J. Gibbon \& L. Allan (Eds.), Timing and time perception (Annals of the New York Academy of Sciences, Vol. 423, pp. 211-227). New York: New York Academy of Sciences.

CATANiA, A. C., \& REYnolds, G. S. (1968). A quantitative analysis of the responding maintained by interval schedules of reinforcement. Journal of the Experimental Analysis of Behavior, 11, 327-383.

ESTES, W. K., \& SKINNER, B. F. (1941). Some quantitative properties of anxiety. Journal of Experimental Psychology, 29, 390-400.

FlaherTy, C. F., \& CHECKE, S. (1982). Anticipation of incentive gain. Animal Learning \& Behavior, 10, 177-182.

FLESHLER, M., \& HofFMAN, H. S. (1962). A progression for generating variable-interval schedules. Journal of the Experimental Analysis of Behavior, $5,529-530$.

HERRNSTEIN, R. J. (1970). On the law of effect. Journal of the Experimental Analysis of Behavior, 13, 243-266.

Hinson, J. M., \& STADdon, J. E. R. (1983). Hill-climbing by pigeons. Journal of the Experimental Analysis of Behavior, 39, 25-47.

Hodos, W., \& BonBRight, J. C., JR. (1972). The detection of visual intensity differences by pigeons. Journal of the Experimental Analysis of Behavior, 18, 471-479.

KilleEn, P. R., Hanson, S. J., \& Osborne, S. R. (1978). Arousal: Its genesis and manifestation as response rate. Psychological Review, 85, 571-581.

MCSWEENEY, F. K. (1992). Rate of teinforcement and session duration as determinants of within-session patterns of responding. Animal Learning \& Behavior, 20, 160-169.

MCSWEENEY, F. K., HATFIELd, J., \& Allen, T. M. (1990). Within-session responding as a function of post-session feedings. Behavioural Processes, 22, 177-186.

MCSweEney, F. K., \& Hinson, J. M. (1992). Patterns of responding within sessions. Journal of the Experimental Analysis of Behavior, 58, 19-36.

MCSWEeney, F. K., \& Roll, J. M. (1993). Responding changes systematically within sessions during conditioning procedures. Journal of the Experimental Analysis of Behavior, 60, 621-640.

MCSweEney, F. K., Roll, J. M., \& CanNon, C. B. (1994). The generality of within-session patterns of responding: Rate of reinforcement and session length. Animal Learning \& Behavior, 22, 252-266.

Mosso, A. (1906). Fatigue (M. Drummond \& W. B. Drummond, Trans.). New York: Putnam. (Original work published 1903)

PapiNi, M. R., \& OVermier, J. B. (1985). Partial reinforcement and autoshaping of the pigeon's key-peck behavior. Learning \& Motivation, 16, 109-123.

REESE, T. W., \& Hogenson, M. J. (1962). Food satiation in the pigeon. Journal of the Experimental Analysis of Behavior, 5, 239-245.

SCHNEIDER, B. A. (1969). A two-state analysis of fixed-interval responding in the pigeon. Journal of the Experimental Analysis of Behavior, 12, 677-687.

WILLIAMS, B. A. (1983). Another look at contrast in multiple schedules. Journal of the Experimental Analysis of Behavior, 39, 345-384.

(Manuscript received June 10, 1994; revision accepted for publication October 4, 1994.) 